\title{
O teletrabalho na pandemia da covid-19: uma nova armadilha do capital?
}

\author{
Bruno Durães (https://orcid.org/0000-0002-7571-0918), \\ Universidade Federal do Recôncavo da Bahia, Cruz das Almas, Bahia, Brasil'.
}

Maria Aparecida da Cruz Bridi (https://orcid.org/0000-0001-8004-1360), Universidade Federal do Paraná, Londrina, Paraná, Brasil".

Renata Queiroz Dutra (https://orcid.org/0000-0003-0736-8556),
Universidade de Brasília, Brasília, Distrito Federal, Brasil"'.

Resumo: Este artigo tem por escopo discutir o fenômeno do teletrabalho, que foi impulsionado em razão do contexto da pandemia do Covid-19 em 2020. Destaca-se a nova narrativa do capital, que, ao tempo que exalta seus benefícios, tende a ocultar os riscos, bem como as possibilidades de reformulação dos ganhos empresariais na exploração do trabalho humano. Para tanto, revisa-se o novo cenário do trabalho, a partir do contexto da denominada "modernização" das relações laborais, considerando os processos de intensificação das jornadas, de apropriação do espaço privado da residência dos trabalhadores, de compatibilização entre trabalho produtivo e reprodutivo, sobretudo por mulheres, de isolamento em relação aos coletivos de trabalho e suas articulações políticas, bem como de sofrimento e adoecimento psíquico. A partir de bibliografia pertinente e da análise de dados secundários sobre o teletrabalho na atualidade, é problematizada a regulação incidente sobre esses trabalhadores como elemento conformador do fenômeno.

Palavras-chave: Teletrabalho. Regulação. Precarização. Pandemia.

\section{Teleworking in the covid-19 pandemic: a new capital trap?}

Abstract: This article aims to discuss the phenomenon of teleworking, which was driven by the context of the Covid-19 pandemic in 2020. It is noteworthy that the new narrative of capital, which, while extolling its benefits, tends to hide the risks, as well as the possibilities for reformulating business gains in the exploitation of human labor. To this end, the new work scenario is reviewed, based on the context of the so-called "modernization" of labor relations, considering the processes of intensifying working hours, appropriating the private space of workers' homes, making work and reproductive tasks compatible, especially by women, of isolation in relation to work groups and their political articulations, as well as psychological suffering and illness. Based on the pertinent bibliography and the analysis of secondary data on teleworking today, the regulation of these workers is problematized as a shaping element of the phenomenon.

Keywords: Home office. Precariousness. Regulation. Pandemic.
Recebido: 29.12.20

Aprovado: 18.06 .21

I. Bruno Durães é professor de sociologia do Instituto de Filosofia e Ciências SociaisIFCS/UFRJ (Rio de Janeiro), professor do Programa de Pós-Graduação em Política Social e Territórios da Universidade Federal do Recôncavo da Bahia (Cruz das Almas, BA) e pesquisador do $\mathrm{CRH}$ / UFBA.

<brunoduraes@ifcs. ufrj.br>.

II. Maria Aparecida da Cruz Bridi é professora associada do Departamento de Sociologia e do Programa de Pós-Graduação em Sociologia da Universidade Federal do Paraná (UFPR), Londrina, PR. <macbridi@gmail. com>.

III. Renata Queiroz Dutra é professora adjunta de direito e processo do trabalho da Faculdade de Direito da Universidade de Brasília (UnB), Brasília, DF. $<$ renata.dutra@unb. br>. 


\section{Introdução}

A

s crises no sistema capitalista repercutem de forma imediata e contundente no trabalho, no mercado de trabalho e no direito protetivo do trabalho. Tem sido assim desde os anos 1970, quando se dá uma transição do regime de acumulação fordista, do emprego estável, protegido, para o regime de acumulação flexível, caracterizado pelo emprego instável, inseguro, precário, nos termos de David Harvey (1999). As alterações nos processos de produção e de organização da produção e do trabalho são fartamente demonstradas pelos estudos do trabalho. Em diversos países desenvolvidos a classe trabalhadora experimenta um profundo processo de precarização do trabalho, mediante piora efetiva nas modalidades de contratação do trabalho, que se propaga afetando a qualidade do emprego e alterando os sistemas protetivos. No caso do Brasil, tais processos desencadearam reformas laborais sob o discurso da modernização do trabalho durante os governos de Fernando Henrique Cardoso (1995-2003), Michel Temer (2016-2018) - com a Lei 13.467 de 2017 - e Jair Bolsonaro (a partir de 2019). O governo Bolsonaro ampliou as reformas neoliberais por meio de medidas como a reforma previdenciária e a extinção do Ministério do Trabalho, transformado em mera secretaria vinculada ao Ministério da Economia (Bridi, 2020a).

O que se assistiu no Brasil, nesse período, foi a franca deterioração dos mercados de trabalho, o aumento do desemprego e a piora da qualidade do emprego, desacompanhados da prometida melhoria dos indicadores econômicos do país. Com esse preâmbulo breve queremos afirmar que a crise do trabalho no Brasil antecede a pandemia da Covid-19, sendo que a crise sanitária "[...] potencializou a fragilidade do mercado de trabalho que vinha em franco processo de deterioração nos últimos quatro anos" (Bridi, 2020b: 142). Essa crise desafia as ciências sociais, no que se refere aos estudos do trabalho a identificar o que, de fato, é novo; quais são as particularidades dessa crise; o que se deve à crise sanitária e o que se deve aos processos políticos, econômicos, sociais e jurídicos que a antecedem.

A literatura que tem se debruçado sobre os reflexos da pandemia no mercado de trabalho demonstra que a Covid-19 impactou a classe trabalhadora dos mais diferentes setores econômicos, públicos e privados, formais e informais. Essa afetação se deu de diversas maneiras, dentre as quais o desemprego, a intensificação de trabalho, a redução dos ganhos e a insegurança aparecem com centralidade. Medida pelo IBGE Pnad Covid-19, entre 20 de setembro e 26 de setembro de 2020 (IBGE, 2020), por exemplo, a taxa de desocupação era de $14,4 \%$. No mesmo período, mais de 15 milhões deixaram de procurar emprego em razão da pandemia ou por falta de trabalho; quase três milhões encontravam-se afastados do trabalho devido ao 
distanciamento social (em maio de 2020, momento de início da referida pesquisa, eram 16,589 milhões de pessoas); 900 mil deixaram de receber remuneração. E, desde o início da pandemia, milhões de trabalhadores passaram a trabalhar remotamente. É sobre esse grupo que nos deteremos neste artigo.

Os trabalhadores remotos, de acordo com os dados da pesquisa IBGE Pnad Covid-19, oscilaram entre 8,914 milhões na semana de 31 de maio a 6 de junho de 2020, maior patamar de trabalhadores que passaram a trabalhar em casa registrado no Brasil, e o menor, que correspondeu a 7,806 milhões entre 13 de setembro e 19 de setembro de 2020. Esse fenômeno do trabalho remoto, também referido como home office e/ou teletrabalho, no qual milhões tiveram o trabalho transferido para o ambiente doméstico como principal medida para se evitar o contágio da Covid-19, favoreceu a experimentação dessa modalidade de trabalho pelos mais diferentes setores econômicos.

A proposta deste artigo é, portanto, analisar criticamente o fenômeno do teletrabaIho, que foi impulsionado em razão do contexto da pandemia do Covid-19, sendo objeto de uma nova narrativa do capital. Essa narrativa, ao tempo que exalta os benefícios do teletrabalho, tende a ocultar os riscos de precarização, nos âmbitos individual e coletivo, bem como as possibilidades de reformulação dos ganhos empresariais na exploração do trabalho humano, numa nova redistribuição de ônus do processo produtivo, que desequilibra ainda mais as já assimétricas relações de trabalho.

A partir de bibliografia pertinente e da análise de dados secundários sobre o teletrabalho na atualidade, o impacto dessa modalidade laborativa sobre os trabalhadores foi problematizado, pondo em cena a desestruturação da regulação da proteção social e laboral. Para cumprir esse percurso, propomo-nos pensar, primeiro, o novo cenário do trabalho, a partir do contexto da denominada "modernização" das relações laborais, considerando como essas inovações são apropriadas por um modelo capitalista predatório, que faz uso da tecnologia para intensificar a exploração e a utiliza, igualmente, para disfarçar juridicamente as relações de trabalho, acentuando processos de precarização e perda de direitos.

Em seguida, para dialogar especificamente com o fenômeno do teletrabalho, indicando o seu uso acentuado a partir do advento da pandemia do Covid-19 e da determinação de isolamento social como estratégia de prevenção coletiva do contágio, propomos uma investigação do teletrabalho a partir do lugar dos trabalhadores nele inseridos, considerando os processos de intensificação das jornadas, de apropriação do espaço privado da residência dos trabalhadores, os desafios de compatibilização 
entre trabalho produtivo e reprodutivo, sobretudo por mulheres, o isolamento em relação aos coletivos de trabalho e a suas articulações políticas, bem como o sofrimento e o adoecimento psíquico. Ademais, a fragilidade da regulação protetiva sobre esses trabalhadores será analisada como elemento conformador do fenômeno.

A partir dessas reflexões, retomaremos os sentidos, usos e riscos da tecnologia e daquilo que se denomina de "modernização" no mundo do trabalho, problematizando as alternativas advindas do contexto pandêmico e a possibilidade de sua continuidade no pós-pandemia. Ao final, apresentaremos nossas conclusões.

\section{Pandemia e teletrabalho: desafios conceituais}

A pandemia da Covid-19 e o seu enfrentamento levou à necessidade do distanciamento social como única forma de evitar o contágio. Empresas, escolas, universidades e outras instituições que puderam adotar o trabalho remoto passaram a fazê-lo. Nesse contexto, diversas dificuldades foram enfrentadas pelos trabalhadores devido à necessidade de terem de se adaptar ao trabalho emergencial remoto (Bridi, 2020a). Esse trabalho constitui uma modalidade de teletrabalho, mas tem distinções, justamente pelo caráter emergencial e por ter remetido categorias profissionais de diversos setores econômicos e de serviços para o trabalho em domicílio. As peculiaridades que esse trabalho assumiu remetem a buscar precisá-lo na realidade do trabalho, visto que se trata de uma modalidade que antecede a pandemia, resultante do regime de acumulação flexível e de avanços tecnológicos que permitiram que certos trabalhos pudessem ser feitos de forma distante do local do contratante.

O teletrabalho, embora fruto da confluência dos sistemas flexíveis e da revolução informacional do último quartel do século XX, não pode ser entendido separado das formas históricas de trabalho domiciliar (em casa, parcial, home office) que o precedem. No entanto, não se confunde com o trabalho em domicílio dos primórdios da industrialização e que retornou com a reestruturação produtiva e a externalização da produção, caso típico do segmento da confecção (Bridi, 2020a). Neste segmento, a exemplo das pequenas fabriquetas de confecções domiciliares, por meio do chamado "trabalho por facção" ou faccionado, como pesquisou Ângela Lima (2009), a confecção de peças em jeans é realizada por partes, até que as peças cheguem prontas à fábrica principal, onde ocorre apenas a inserção da etiqueta. Ou do ramo de produção agrícola de fumo (como no caso do Recôncavo Baiano), em que parte do trabalho que já era feito por agricultores familiares em pequenas produções ou que já vinha sendo produzido sob a forma de parceria pelas mulheres no Recônca- 
vo, que se ocupam de enrolar e tratar parte do fumo em suas casas e depois repassam para as empresas produtoras de charutos.

São, portanto, antigas formas de trabalho realizadas em domicílio, remontando a contextos pré-capitalistas e se apresentando, no capitalismo, tanto em atividades laborais compatíveis com a chamada economia de subsistência, que integram a informalidade, como outras atividades informais - a chamada "nova informalidade" (Krein \& Proni, 2010) - realizadas em favor de empresas e atividades econômicas organizadas, porém por meio de fraudes e outras formas de falseamento dos vínculos empregatícios. Essa já é uma face do trabalho realizado em casa antes da pandemia de Covid-19, marcado pela precariedade, pela retirada de direitos e pelo envolvimento do trabalho familiar, com perigoso engajamento do trabalho infantil. Nesse sentido, o Brasil possui um histórico de formas de trabalho domiciliar que se coloca, não no espectro do novo, mas no que há de mais arcaico e contraditório em nossas relações capitalistas. Essas formas de trabalho, contudo, não se confundem com o teletrabalho também realizado no domicílio dos trabalhadores.

O aumento do teletrabalho, no período recente, sobretudo para extratos mais qualificados da força de trabalho, é uma realidade desde o advento da revolução informacional. Resultantes das novas tecnologias da informação e comunicação (TIC), também podemos incluir nesse conjunto outras formas de trabalho já enquadradas naquilo que genericamente se denomina "uberização" (Slee, 2017) ou trabalho por demanda, mediado pelas plataformas digitais. Eis que, para muitos desses aplicativos, tem-se um conjunto de trabalhadores informais que prestam alguns serviços de casa, em seus computadores e/ou celulares, para empresas-aplicativos que os enquadram, irregularmente, como parceiros. Na área de tecnologia da informação, essas relações são recorrentes, assim como também no jornalismo e na tradução, muitas vezes associadas ao fenômeno da pejotização. Nem todas essas atividades, embora sejam realizadas externamente às unidades produtivas empresariais, de forma remota, se enquadram como teletrabalho.

Existem diferenças entre os termos trabalho remoto, em casa/home office e/ou teletrabalho, mas nesse texto os conceitos serão tratados como sinônimos, tal como se disseminou no contexto pandêmico em 2020. As referências distintas, entretanto, não pretendem contemplar o trabalho remoto feito na rua via equipamento eletrônico, mas sim o trabalho remoto realizado em casa. Como observa Daniela de Oliveira sobre o conceito de home office:

É uma categoria polissêmica que estabelece a diferença entre trabalho doméstico - aquela forma tradicional de trabalho em casa 
[...] - do teletrabalho marcado pela introdução das tecnologias informacionais [...] (Oliveira, 2017: 21).

O teletrabalho, do qual tratamos neste texto, embora realizado no espaço doméstico, tem características distintas, tratando-se de atividades próprias do trabalho digital, que envolve o uso de meios eletrônicos, computadores, smartfones, conexão de internet, plataformas digitais e outras. Tanto a literatura nacional como internacional destacam as

[...] imprecisões conceituais, que se devem, em grande parte [...] ao fato de poder ser realizado em diferentes espaços, mediado por diferentes modalidades contratuais e frequência, cujo critério básico adotado é o da realização fora da empresa e mediado pelas tecnologias de informação e comunicação (Bridi, 2020a: 176).

As dificuldades de conceituação do teletrabalho desafiam os estudiosos do trabaIho e, também, os órgãos públicos na obtenção de dados oficiais sobre quantos e quem são os trabalhadores remotos, em teletrabalho. Tais dificuldades, tanto no Brasil como em todo o mundo, se devem também à variedade de formas de trabalho. Antes da crise sanitária provocada pela Covid-19, já existiam formas mistas de trabalho, realizadas, em parte, em casa e, em parte, no espaço produtivo/ institucional, a exemplo do trabalho docente no Brasil, sobretudo ante a falta de estrutura para trabalho interno (preparação de aulas, correção de provas, pesquisa, produção acadêmica) em parte significativa de escolas e universidades. Esse tipo de combinação também pode ser verificado entre médicos, advogados, contadores, jornalistas como decorrência da invasão do tempo de repouso por demandas de trabalho. É uma tendência de crescimento no mundo, com maior presença em países desenvolvidos e menor presença nos países emergentes e periféricos (Bridi, 2020a). As configurações desse trabalho no contexto da pandemia e nos períodos que a antecederam, de fato desafiam os pesquisadores a analisarem e a compreenderem as implicações desse trabalho também para o período pós-pandemia.

No período do trabalho remoto emergencial, não há relação entre a ampliação do trabalho remoto e a melhoria das condições de vida da classe trabalhadora, como se pode depreender das pesquisas realizadas no contexto da pandemia, como demonstraremos posteriormente. A conversão das formas de trabalho presenciais em remotas, no contexto pandêmico, consistiu em contingência sanitária. Superado esse momento, a manutenção ou reversão das relações de trabalho remoto decorre muito mais de uma avaliação de sua viabilidade para o capital - não só pela redução de custos com a estrutura produtiva e compartilhamento desses custos com 
os trabalhadores, mas pelas possibilidades abertas de intensificação da exploração dos trabalhadores - do que para a vida e bem-estar dos trabalhadores.

A compreensão do fenômeno do teletrabalho não pode ser dissociada das trajetórias comuns do trabalho, a respeito das quais já acumulamos repertório crítico e avaliações empíricas. Assim, é importante nos afastarmos de uma narrativa que, ao derramar uma série de expectativas positivas sobre o fenômeno, apontando apenas para possibilidades de futuro, possa recair em uma avaliação irreal ou ilusória. O teletrabalho, nesse contexto da pandemia, tem sido apontado como "privilégio", dada a devastação do trabalho e do mercado de trabalho (Oliveira \& Pochmann, 2020) potencializada pela pandemia. A ideia de privilégio se dá em face ao perfil da parcela da classe trabalhadora que pode transferir seu trabalho para o ambiente doméstico, com possibilidade de manutenção de seus empregos e remunerações. Mas, de fato, as condições desse trabalho, desnudadas empiricamente e por meio de literatura crítica, recolocam os imensos desafios postos aos trabalhadores para impedir o avanço da precarização do trabalho (Druck, 2011).

Embora o contexto empurre parte significativa da classe trabalhadora para essa realidade, a despeito das nossas individualidades e interdependências constitutivas, é certo que não é viável que todas as atividades necessárias à reprodução social sejam realizadas de casa ou à distância (no caso do trabalho feito na rua via celular, tablete ou notebook). Sem dúvida, vive-se hoje um momento que levou a essa situação por uma estratégia coletiva de saúde pública (Covid-19). Porém, as perspectivas de implementação definitiva dessa modalidade, bem como a crença de que isso representaria vantagens para o mundo do trabalho são controversas.

O teletrabalho apresenta-se como fenômeno social em ebulição diante de uma realidade em mutação. Com isso, cabe à ciência social a análise crítica, mas com mediação e aproximações sucessivas, que se proponham a "duvidar do trivial".

Nessa via, pressupor a generalização do trabalho remoto bem como associá-lo inevitavelmente à modernidade ou a um sentido de "progresso" é correr o risco de cair na narrativa do mercado, que pode ser apenas mais um ardil da ordem do capital.

\section{A pandemia e os rearranjos do capital: rumo ao teletrabalho}

Pesquisa publicada pelo Instituto de Pesquisa Econômica Aplicada (Ipea, 2020) revela que, antes da pandemia, já havia um significativo uso do teletrabalho no Brasil. O país ocupa a 45a posição em uma lista de 86 países classificados em relação à 
proporção de uso do teletrabalho, apresentando $25,65 \%$ de teletrabalho. No contexto latino-americano (Ipea, 2020), o país se destaca, sendo o terceiro de doze países que constam do estudo, atrás apenas do Chile $(25,74 \%)$ e do Uruguai $(27,28 \%)$. Essa pesquisa aponta uma correlação positiva entre renda per capita e proporção de uso do teletrabalho, demonstrando que o desenvolvimento econômico de um país tende a gerar mais oportunidades de trabalho dessa modalidade.

O Ipea também realizou uma projeção das atividades que têm potencial de serem convertidas ao teletrabalho no contexto da pandemia, valendo-se de dados do primeiro trimestre da Pnad Contínua de 2020, e concluiu pela existência de um percentual de pessoas em potencial de teletrabalho de cerca de $22,7 \%$, que corresponde a 20,8 milhões de pessoas (Ipea, 2020). Destacam os pesquisadores que, considerando as diversidades regionais, o Distrito Federal apresenta o maior percentual de potencial de teletrabalho (31,6\%), o que corresponde a cerca de 450 mil pessoas, ao passo que o estado do Piauí apresenta o menor percentual em potencial de teletrabalho (15,6\%), correspondendo a cerca de 192 mil pessoas, que poderiam potencialmente estar em teletrabalho.

Novamente as condições econômicas apresentam-se como relevantes para o fator do teletrabalho, devendo ser aliadas a esse dado a maior presença do setor público como setor com potencial de teletrabalho, o que qualifica o Distrito Federal, centro administrativo do país, nesse conjunto.

Em pesquisa realizada por Oliveira (2017), em período que antecede a pandemia, a autora, ao se debruçar sobre o teletrabalho de uma categoria específica, a de trabalhadores em tecnologia da informação - portanto, um grupo economicamente favorecido entre os quais o teletrabalho já se disseminava -, observou que essa não era uma realidade isenta de riscos aos trabalhadores. O estudo apontou para o elemento de precarização que envolve o trabalho remoto e a quebra de fronteira entre espaço público e privado. Entre os problemas identificados estavam os riscos físicos à saúde, bem como a falta de apoio de equipamentos ergonômicos, ausência de descanso, com noites sem dormir e excesso de trabalho.

Os trabalhadores entrevistados por Oliveira (2017) relatavam a preferência por uma forma híbrida de trabalho, com o teletrabalho combinado com atividades presenciais, visto que nem sempre era uma opção. A autora sintetizou a condição do home office como o "trabalho sem fim", dado o excesso de trabalho e a ausência de limites entre o tempo de repouso e a jornada como consequência do aparato tecnológico e comunicacional. Daniela de Oliveira se refere às incontáveis 
[...] mensagens e chamadas (WhatsApp, telefone, e-mails), recebidas pelos trabalhadores digitais de colegas de equipe e/ou de supervisores, são, muitas vezes, percebidas como parte da lógica do trabalho (Oliveira, 2017: 167).

Mesmo fora da jornada regular de trabalho, esses trabalhadores não se desconectavam, seja acessando e-mail, respondendo mensagens ou desenvolvendo algumas outras tarefas. Essas condições tenderam a se generalizar no trabalho remoto durante a pandemia em 2020, chegando, segundo os dados do IBGE Pnad-Covid-19, a quase nove milhões de trabalhadores remotos, que tiveram suas atividades profissionais transferidas para o domicílio.

Para apreender e analisar as condições desse trabalho remoto, uma pesquisa chamada "O trabalho remoto/home office no contexto da pandemia Covid-19", realizada por um grupo de pesquisadores e estudantes da Universidade Federal do Paraná e da Rede de Estudos e Monitoramento Interdisciplinar da Reforma Trabalhista (Remir) entre 5 e 17 de maio de 2020 - portanto, já no contexto pandêmico -, por meio de entrevistas coletadas virtualmente e que contou com 906 respondentes do Brasil, produziu as seguintes conclusões sobre teletrabalho (trabalho remoto):

[...] o trabalho remoto no momento da pandemia do Coronavírus sobrecarregou os trabalhadores no sentido de mais trabalho, em termos de horas e dias trabalhados, gerando um ritmo mais acelerado. [...] Os custos com os quais os trabalhadores têm que arcar quando realizam home office e a imbricação entre tempo de trabalho e tempo de não trabalho são outros elementos recorrentemente mencionados pelas pesquisas que enfatizam as desvantagens que o trabalho remoto gera para o trabalhador e, em certa medida, uma perda da qualidade no trabalho de vários profissionais, segundo relato dos mesmos (Bridi, Bohler \& Zanoni, 2020: 43-44).

A pesquisa mostra que apenas $8,4 \%$ dos respondentes trabalhavam seis dias por semana antes da experiência do teletrabalho, sendo que esses respondentes passaram a representar $18 \%$ nessa nova condição, o que representa um aumento de $115,78 \%$. Outro dado alarmante é o de que, antes, 2,32\% dos pesquisados trabaIhavam sete dias por semana e, após a condução ao teletrabalho, os sujeitos imbuídos dessa condição passaram a representar $17,7 \%$, o que representa um aumento percentual de $666,66 \%$ de trabalhadores que prestam serviços todos os dias da semana, sem descanso. Dos/as pesquisados/as, 48,45\% passaram a trabalhar mais: no geral, cerca de $25 \%$ afirmaram que tiveram aumento de metas de produtividade (Bridi, Bohler \& Zanoni, 2020). Estes dados parecem indicar o aumento da explo- 
ração do trabalho no contexto do teletrabalho, bem como sua intensificação. Essa pesquisa - que contou com 590 respondentes do setor público e 303 do setor privado e 13 respondentes de organizações sem fins lucrativos (ONGs) -, demonstrou que as condições de trabalho foram profundamente alteradas,

[...] seja pelo fato de os trabalhadores terem que trabalhar a partir de suas casas, em espaços nem sempre adequados, seja pelas condições de trabalho, envolvendo a realização de múltiplas tarefas profissionais e domésticas, de novos aprendizados concomitantes às atividades de trabalho, caso dos docentes, por exemplo, que tiveram de aprender a gravar aulas, testar imagens, sons, postar tarefas, acompanhar, avaliar etc., tudo de forma remota, muitas vezes com apoios apenas de tutoriais. Isso representou, para muitos, jornadas estendidas e não pagas (Bridi, Bohler \& Zanoni, 2020: 189).

Entre os aspectos negativos do trabalho remoto, destacam-se o isolamento dos trabalhadores e o empobrecimento da experiência de socialidade promovida pelo trabalho, que repercute sobre a saúde mental dos envolvidos, como também já havia sido apontado por Oliveira (2017) em pesquisa sobre os trabalhadores de tecnologia da informação.

A metade dos entrevistados relatou como aspectos positivos do trabalho remoto a flexibilidade dos horários de trabalho, a economia do tempo de transporte e a disponibilidade de maior proximidade com a família. Contudo, quase 50\% (48,45\%) disseram que passaram a trabalhar mais (Bridi, Bohler \& Zanoni, 2020: 26).

Embora os trabalhadores respondentes da pesquisa sejam, em sua maioria (92\%), de elevada escolaridade, saltaram aos olhos as condições precárias no que se refere ao trabalho realizado no domicílio, visto que apenas 30\% informaram terem condições de trabalho excelentes por contarem com espaço, mesa e cadeira para o trabalho. Os demais afirmaram serem razoáveis (por terem mesa e cadeira) e péssimas, por não terem espaço próprio de trabalho, mesa e cadeira adequados (totalizando 70\%). Somam-se a esses problemas as dificuldades relativas à falta de equipamentos adequados ou modernos apontadas por 25,84\%; a dificuldade em atuar com o computador e os aplicativos para $20,03 \%$ e o fato de ter que tomar decisões sozinha/o para $19,42 \%$. São dificuldades maiores ou menores, dependendo da ocupação, da categoria profissional. Nesse sentido, novos estudos precisarão aprofundar esses dados e inter-relacionar as respostas positivas e negativas, bem como contemplar extratos sociais populares, com menor escolaridade, e que não sejam majoritários do serviço público. 
Portanto, o teletrabalho no contexto da pandemia é experienciado de forma distinta por trabalhadores engajados em trabalhos intelectuais, que já manejavam as tecnologias quando trabalhavam presencialmente, e aqueles trabalhadores, sobretudo do setor de serviços, que passaram a ser conduzidos ao teletrabalho numa adaptação de suas funções em decorrência do contexto de pandemia.

O estudo também revelou que o trabalho remoto impactou desigualmente a classe trabalhadora. As mulheres foram mais afetadas, uma vez que as tarefas domésticas e o cuidado com os filhos permaneceram atribuídos de forma assimétrica às mulheres, impactando ainda mais aquelas com filhos (Bridi, Bohler \& Zanoni, 2020). Os dados da pesquisa demonstram, assim, que não se pode perder de vista as distinções de gênero envolvidas na experiência do teletrabalho, tendo em vista que a afetação do cuidado ao gênero feminino implica em atividades produtivas no ambiente doméstico com grande ônus para a conciliação de tarefas, as atenções e as demandas por parte das mulheres, sobretudo em um cenário de suspensão das atividades escolares de crianças e adolescentes. Também a pesquisa empreendida por Bárbara Castro (Cuidar verbo coletivo, 2020) dá conta de registros completamente distintos em relação ao aproveitamento do tempo e à distribuição do trabalho ao longo do dia por homens e mulheres em teletrabalho, mesmo antes da pandemia.

A Organização Internacional do Trabalho (OIT), no balanço geral sobre a pandemia, a crise econômica e os impactos no trabalho, concebeu o teletrabalho como um recurso importante para a conservação de empregos durante a pandemia, sobretudo diante da projeção no início da crise sanitária de desemprego de 25 milhões de pessoas em razão da Covid-19. Entretanto, recomenda que essa modalidade deva ser exercida em condições seguras, envolvendo o estabelecimento de elementos subjetivos como apoio gerencial, treinamento e suporte técnico adequados (OIT, 2020).

Essa condição segura, entretanto, dificilmente tem sido observada no cenário de "improviso" que a pandemia impõe, associado ao comportamento tendencial das relações de trabalho no capitalismo que caminham para a acentuação da exploração, evidenciada também no teletrabalho, na medida em que os trabalhadores acabam arcando com parte dos custos do trabalho, como revelou a pesquisa sobre o trabalho remoto no contexto da pandemia. Na já referida pesquisa, coordenada por Maria Aparecida Bridi (Bridi, Bohler \& Zanoni, 2020), constatou-se que, do total de 906 respondentes, 470 (52\%) informaram aumento de gastos pessoais para realizar o trabalho remoto relativos a dispêndios diretos como compra de computadores, acessórios, conexão de rede etc. Os 436 (48\%) que afirmaram que não tiveram aumento de gastos pessoais possivelmente não computaram as despesas com energia, conexões de rede, por já terem os equipamentos de informática antes 
da pandemia. Alguns desses trabalhadores informaram que o aumento de gasto foi compensando com a redução das despesas com transporte, estacionamento etc. Esse, contudo, é um dos gargalos do teletrabalho (Bridi, Bohler \& Zanoni, 2020).

Portanto, seguindo o vetor já em curso no conjunto do que se denominou revolução 4.0 (Schwab, 2016) ou capitalismo de plataforma (Srnicek, 2016), ou mesmo acentuando-o em função do cenário pandêmico, as perspectivas para o teletrabaIho desafiam a classe trabalhadora, por meio da ação coletiva e de seus sindicatos e demais organizações em defesa do trabalho a estabelecer os limites dessa modalidade de trabalho.

O teletrabalho e a nova configuração social:

os riscos do "novo" a partir de velhas estruturas

Ricardo Antunes (2020) considera que o capital e os seus gestores têm feito de determinadas práticas - como o home office, o teletrabalho e o ensino à distância - um verdadeiro laboratório de experimentação. O momento do pós-pandemia da Covid-19 tende a ser atravessado por um significativo crescimento do teletrabalho, tendo em vista as vantagens que esse laboratório demonstrou do ponto de vista empresarial (Antunes, 2020). Nesse sentido, o teletrabalho, que se caracteriza pela maior individualização do trabalho e o maior distanciamento social, tende a implicar em "[...] menos relações solidárias e coletivas no espaço de trabalho (onde floresce a consciência das reais condições de trabalho)" (Antunes, 2020: 19), assim como inclina-se a desafiar os sindicatos em face da eliminação tendencial dos direitos do trabalho. Com o fim da separação entre tempo de trabalho e tempo de vida (ou trabalho e não trabalho) identificados pelas pesquisas empíricas sobre o trabalho remoto, vivenciaremos mais

[...] duplicação e justaposição entre trabalho produtivo e trabalho reprodutivo, com clara incidência da intensificação do trabalho feminino, podendo aumentar ainda mais a desigual divisão sociossexual e racial do trabalho (Antunes, 2020: 19).

Embora vislumbre alguns pontos positivos aos trabalhadores, notadamente relacionados à eliminação dos deslocamentos, à flexibilidade dos horários e ao convívio familiar, Antunes adverte para o fato de ser profundamente desigual a relação entre capital e trabalho, de modo que a relação entre o que se perde e o que se ganha tende a acompanhar tal desigualdade. Assim, a equação entre vantagens e desvantagens do teletrabalho deve ser medida por lentes atentas às desigualdades estruturais dessa relação. Ademais, precisa considerar os experimentos do capital no período pandêmico, sobretudo, no tocante à transferência do ônus da crise à 
classe trabalhadora, potencializando mecanismos de exploração do trabalho (Antunes, 2020: 20).

Na esteira dos prós e contra do teletrabalho, é importante observar a dimensão da individualização do trabalho, já identificada por Cinara Rosenfield e Daniela Alves (2011). O capitalismo historicamente precisou do trabalho coletivo, feito por diversos trabalhadores de forma combinada. Agora, embora o capitalismo ainda necessite dessa forma coletiva, ele dela se vale de modo pulverizado digitalmente. Mas como isso repercute na lógica da ação integrada do trabalho feito por equipes? Ao ser instado a criar o espaço do trabalho em sua casa (e, por vezes, por conta própria) e ao produzir de forma isolada, sem conhecimento dos modos de agregação do seu trabalho às demais etapas do processo produtivo, o trabalhador estaria a experimentar um novo nível de alienação? Como se dará essa agregação dos diversos trabalhos realizados para produção do resultado coletivo?

Essas questões devem ser pensadas em conjunto com as já mapeadas preocupações quanto à intensificação do trabalho, às limitações do teletrabalho em relação aos grupos menos qualificados, bem como à intersecção entre condições de gênero e raça, que repercutem em locais de moradia e formas de vivenciar o espaço privado e interferem, diretamente, nas condições para o exercício do teletrabalho.

Jorge Luiz Souto Maior (2003) apontava, no começo do século XXI, que a tecnologia que permite o home office revela uma nova contradição, que é a desconstrução dos limites entre esfera do trabalho e esfera do privado (do íntimo, familiar). O teletrabalho tem um potencial avassalador em afetar a subjetividade das pessoas e adentrar os espaços mais recônditos de nossas vidas (que é a esfera do pessoal e familiar). O que vem fantasiado de flexibilidade e conforto na realização do trabalho no espaço doméstico, com suposta satisfação e manejo do tempo livre pelo empregado, significa, na prática, a apropriação do espaço doméstico do trabalhador em prol da organização capitalista, com o desenvolvimento de novos grilhões, com potencial de afetar as condições de trabalho, a vida fora do trabalho (que pode deixar de existir de forma definitiva) e as possibilidades da socialização a partir do trabalho, contribuindo para a dimensão do adoecimento psíquico que já vinha prevalecendo nessa fase do capitalismo.

Assim, a forma como a tecnologia vem sendo utilizada também se apresenta como fonte de sofrimento, alienação e estresse nunca vivenciada: a sociedade da hipertecnologia é também a sociedade dos doentes psíquicos, da ansiedade, da frustração e da depressão. Nesse sentido, o discurso favorável ao teletrabalho, por meio da exaltação das tecnologias, ancora-se não só na ocultação de seus impactos noci- 
vos na saúde, lazer, socialização e resistência dos trabalhadores, como também em uma rendição diante do cenário de desemprego, informalidade e grande submissão do trabalho ao capital.

Nessa perspectiva, uma outra ordem de questões vem à tona: quais sofrimentos subjetivos surgirão a partir do trabalho realizado em domicílio, sobretudo diante da perspectiva invasiva das câmeras e microfones que tudo captam no ambiente privado? O avanço do adoecimento mental no cenário da pandemia (OMS, 2020) pode ser atribuído, além das adversidades de saúde coletiva, dos reiterados lutos e do isolamento, também aos excessos decorrentes da exploração do trabalho por meio do teletrabalho?

Para além dos já mencionados incrementos da intensidade do trabalho e para além da superação das fronteiras entre o tempo de trabalho e o tempo de não trabalho, entre o espaço de trabalho e o espaço privado, há que se ter em conta que são dimensões desse processo a facilitação da cobrança e das pressões das chefias por meio das tecnologias digitais, bem como a fragilização das resistências no trabalho. O aumento do nível de exploração e a redução das possibilidades de defesa do indivíduo em face da organização do trabalho (Dejours, 2006), que são proporcionadas pelo isolamento e pela necessidade de lidar com novas dinâmicas de trabalho, podem, em grande medida, invalidar as defesas já desenvolvidas pelos sujeitos, demandando a articulação de novas defesas, que possam ser sustentadas diante do novo modo de ser da organização do trabalho. Essa sobrecarga de demandas e a frustração em relação às práticas anteriores são fatores de sofrimento no trabaIho: não poder partilhar com outros trabalhadores de forma imediata e via contato pessoal angústias, sentimentos e perspectivas, assim como ser privado de construir efetivamente laços de afeto e identidade, os quais passam por sentir o outro através da proximidade física (identidade e reconhecimento), são experiências dramáticas. Tais experiências podem se aprofundar em cenários de sofrimento, dando azo ao perecimento da saúde mental e comprometendo o bem-estar no trabalho.

O momento de convivência interpessoal no trabalho é crucial para a ação coletiva e a atuação em defesa de seus direitos, de modo que o isolamento e a imposição de relações virtuais também comprometem as dimensões de resistência e construção dialética no trabalho.

Além da dimensão do isolamento e da fragilização das defesas, Marcelo Veras (UFRB TV, 2020) remonta a uma sensação de culpa que tende a ocorrer com os trabalhadores em teletrabalho nesse momento, em razão das dificuldades de se atingir as metas impostas ou autoimpostas, enfrentando, em razão disso, sofri- 
mento/frustação de um desejo não realizado (UFRB TV, 2020), dado esse também corroborado pelos depoimentos dos trabalhadores no âmbito da pesquisa sobre o trabalho remoto no contexto da pandemia já referida, no qual expressavam a angústia decorrente da sensação de não rendimento no trabalho ${ }^{1}$. Giovanni Alves (2011), ao identificar o processo de captura da subjetividade ou a sujeição do trabalho ao capital, a qual envolve um conjunto de valores das empresas que passam a ser vivenciados pelo trabalhador através da ideologia da corporação/empresa, oferece chaves de compreensão para a análise dos efeitos que a presença sinuosa do trabalho na vida laboral, a partir das dinâmicas do teletrabalho, podem produzir nos modos de subjetivação e patologias mentais.

A corrosão subjetiva vivida pelos trabalhadores no capitalismo moderno - e dito flexível - gera um processo de sofrimento psíquico, sobretudo para aqueles que não conseguem aderir à lógica da flexibilidade imposta e à ruptura promovida em relação aos laços sociais, subjetivos e culturais anteriores (Sennett, 2012). Esse cenário parece adquirir potenciais ainda mais profundos com a dinâmica invasiva e, sobretudo, desarticuladora das relações reais, que o teletrabalho enseja. A lógica neoliberal que, segundo Pierre Dardot e Christian Laval (2016), expandiu-se para além da economia e da política, atingindo a alma das pessoas e gerando uma nova racionalidade individualista, tende a se potencializar com as formas de teletrabalho que atomiza ainda mais os trabalhadores.

\section{A persistência da precarização: o teletrabalho entre reformas laborais}

Outro aspecto relevante a ser considerado, na atual conformação do teletrabalho, é que sua regulamentação, no Brasil, ocorreu no contexto mais amplo das reformas laborais de austeridade e desproteção trabalhista, que foram forjadas a partir do discurso neoliberal (Druck, Dutra \& Silva, 2019).

Daí porque o velho fenômeno do trabalho em domicílio, quando finalmente regulamentado, recebeu tratamento jurídico incompatível com a tutela protetiva de todos os riscos que foram apontados nos itens anteriores. A regulamentação introduzida pela Reforma Trabalhista de 2017 se coloca como aval para a normalização de uma série de relações que já se desenvolviam de forma ilegal, uma vez que, nos termos de José Dari Krein e Roberto Véras de Oliveira (2019), cria um cardápio de opções de contratos de trabalho flexíveis e precários.

A análise da regulamentação do fenômeno nos mostra que, apesar da novidade representada pela realização virtual do trabalho, também há elementos que per-
1. Conforme depoimento de uma trabalhadora do setor público, em trabalho remoto, citada por Bridi (2020a): "A impressão que tenho é que trabalho muito mais e rendo muito menos. Em apenas dois meses já sinto algumas dores nas costas por conta de a estação de trabalho não ser a mais adequada. Sinto pressão para 'mostrar que estou presente' através de produtividade, quando no trabalho presencial isso não existia." Outros depoimentos no referido estudo atestam as dificuldades experimentadas pelos trabalhadores remotos no contexto da pandemia. 
mitem vislumbrar continuidades para a regulação, uma vez que, antes mesmo do fenômeno do trabalho digital, não havia nada na legislação trabalhista que exigisse a presença física ou direta do empregado no ambiente laboral do empregador para que se configurasse o vínculo empregatício e para que os direitos fossem assegurados, como aliás previa expressamente a redação original do art. 6ㅇ da Consolidação das Leis do Trabalho (CLT). Por isso mesmo, o trabalho em domicílio já era admitido na ordem jurídica brasileira, embora carente de prescrições específicas.

A regulamentação do teletrabalho por diversos países "[...] expressa tendências de garantir segurança jurídica para as empresas" (Bridi, 2020a: 181). Destaca a autora, no entanto, que em certos contextos,

[...] países como a França, a Itália e, recentemente, a Argentina asseguraram os direitos dos trabalhadores à desconexão, proteção de dados e saúde dos trabalhadores. [Outros países, no entanto,] caso do Brasil e da Espanha, por exemplo, que também regularam essa modalidade, favorecem a negociação individual (Bridi, 2020a: 181)

No Brasil, em 2011, a CLT passou a prever expressamente, no art. 6으, que os meios

[...] informatizados de comando, controle e supervisão se equiparam, para fins de subordinação jurídica, aos meios pessoais e diretos de comando, controle e supervisão do trabalho alheio (Brasil, 2011).

Ou seja, o comando e o controle do trabalho pelo empregador, ainda que mediado por tecnologias, é o que basta para a configuração do vínculo de emprego e o acesso do trabalhador a direitos.

A regulamentação específica do teletrabalho se deu com a Reforma Trabalhista de 2017 (Brasil, 2017), nos artigos 75-A a 75-E da CLT. A legislação é lacônica e tem conteúdo flagrantemente patronal: ao seguir a linha do restante da reforma, permite a condução do trabalhador ao teletrabalho por acordo individual, remete também para o acordo individual a definição da distribuição dos custos com os equipamentos e serviços necessários ao desempenho do trabalho e, mais grave, estabelece que o trabalhador em teletrabalho está excluído das disposições relativas ao controle de jornada, o que significa dizer que ele não tem direito ao recebimento de horas extraordinárias por eventuais excessos.

A lei presumiu que não seria possível o controle do tempo do trabalho pelo fato de o trabalhador estar trabalhando remotamente, embora o vínculo de emprego 
pressuponha a possibilidade do exercício remoto do controle e vigilância do empregado. A lei também limitou a responsabilidade do empregador pelas normas de saúde e segurança do trabalho ao ato de instruir o trabalhador a esse respeito, sem desdobramentos adicionais como o monitoramento físico e psíquico do trabalho por meio de exames médicos adicionais aos já obrigatórios por lei.

Essas disposições mínimas colocadas para o teletrabalho ficam muito aquém daquilo que a OIT prescreve como condição para o exercício do teletrabalho em condições adequadas, incluindo o contexto da pandemia. A OIT considera relevante o estabelecimento de elementos subjetivos como apoio gerencial, treinamento e suporte técnico adequado, com vistas a conter os efeitos nocivos do isolamento, liberdade para que o trabalhador controle o tempo e as estratégias de trabalho, bem como definição clara de expectativas pelo empregador (OIT, 2020).

Portanto, é preciso observar que o silêncio da legislação sobre questões que se revelam como problemáticas centrais para o trabalhador que vivencia o trabalho remoto, bem como sobre pontos considerados relevantes pelas organizações multilaterais que cuidam do tema, revelam que a questão do teletrabalho acaba por ser relegada ao terreno da regulação privada, no qual o empregador pode exercer seu poder sobre o empregado, sem possibilidades concretas de resistência, nem mesmo na dimensão coletiva. O caminho aberto para a intensificação da precarização encontra guarida no aparato regulatório neoliberal.

\section{Para além do teletrabalho:}

os sentidos, os usos e os riscos da tecnologia no trabalho

A pandemia do Coronavírus mostrou as faces trágicas da globalização e dos caminhos hegemonizados pelo capitalismo no mundo. Além das vulnerabilidades daqueles que estão desamparados pela tela de proteção social, que foram acometidos pelo desemprego ou pela queda da renda, ou que precisam trabalhar em condições de risco e exposição ao contágio, muitos dos que continuam trabalhando passaram a enfrentar os desafios decorrentes do teletrabalho.

Embora reconhecendo que o trabalho emergencial remoto cumpriu importante medida sanitária e, ao mesmo tempo, assegurou empregos (públicos e privados), o olhar crítico proposto nesse artigo visa evitar uma "fetichização da tecnologia" ou um mito salvacionista do mundo digital em face desse cenário. As perspectivas do capitalismo global têm orbitado em torno de dois grandes elementos:

i. reduzir o tempo ocioso ou o não trabalho, seguindo a máxima de que tempo é dinheiro; e 
ii. diminuir o custo de produção, com especial atenção para os custos do trabalho.

Tivemos também, durante todo o século XX, diversos processos de expansão da tecnologia e busca pela automação industrial. A automação, muitas vezes, foi sustentada a pretexto de libertar o trabalhador da função pesada e do sofrimento do trabalho, mas, na prática, tem sido implementada com intencionalidades e seletividades que culminam em incrementar o desemprego estrutural, ao passo que intensificam o trabalho daqueles que persistem empregados/ocupados.

A tecnologia, apesar de suas grandiosas contribuições para humanidade, quando utilizada tão somente a serviço do capital, aprisiona as pessoas, gerando dependência e controle nunca vistos antes, funcionando ainda como forma de dominação das massas, nos moldes de um capitalismo de vigilância (Zuboff, 2018).

Nesse sentido, cabe observar que a tecnologia não possui usos e sentidos intrínsecos, mas apenas se exterioriza com a mediação e a programação humana. Mesmo a denominada inteligência artificial, foi criada por seres humanos e o trabalho de programação ali contido permanece como processo criativo e fonte de valor e de riqueza social, direcionados para os fins para os quais a programação se orientou.

\section{Considerações finais}

Com o teletrabalho rompe-se a fronteira entre espaço do trabalho/da produção e espaço da família/privado. Essa ruptura revela-se perigosa e apresenta riscos que vão desde a intensificação da exploração do trabalho e o aumento da quantidade de horas trabalhadas, sem controle ou contrapartida, até a quebra de autonomia/ liberdade, o sofrimento e o adoecimento mental.

Isso afeta diretamente o trabalhador envolvido, seus coletivos de trabalho e, também, seus conjuntos familiares. Ou seja, o trabalho de estilo digital e remoto (teletrabalho) é uma forma de trabalho em metamorfose, que, embora apareça com nova roupagem no contexto atual, pode significar mais do mesmo, no sentido de uma nova face das estratégias do capital para incremento da exploração e ultrapassagem dos limites que as resistências dos trabalhadores historicamente construíram.

Embora apresentado como algo positivo e "moderno", as experiências enredadas no teletrabalho, em uma perspectiva voltada à acumulação de capital, revelam-se recheadas de contradições, na busca constante do lucro/produtividade e da redução de custos com o trabalho. Mais do que nunca, intensifica-se um processo de 
captura da subjetividade do trabalho através de aparatos tecnológicos digitais, que parece gerar uma lógica de exploração, controle e vigilância jamais vista, traduzida em múltiplos aprisionamentos, opostos à ideia de tecnologia enquanto instrumento de liberdade.

Isso é ainda mais grave porque a legislação brasileira sobre o tema não revela escopo protetivo compatível com as preocupações externadas neste artigo, tampouco com as diretrizes estabelecidas pela Organização Internacional do Trabalho.

De fato, estamos imersos em novas formas de trabalho e de vida e atravessamos momento de profundas transformações, que se sobrepõem continuamente. Essas mudanças, que hoje são atribuídas às tecnologias, devem ser enxergadas também a partir de chaves sociais, culturais e econômicas diversas e existentes na história, e não apenas no sistema capitalista ocidental.

Portanto, é preciso desmitificar a fábula de que a tecnologia aponta para um caminho inexorável e unidirecional, ou mesmo que sua implementação acontecerá, em todo o mundo em um mesmo ritmo. Certamente, há elementos estruturais do capitalismo e de sua lógica perversa que apontam continuidades. E o teletrabalho, a depender das formas de sua regulação, de realização e de conteúdo, pode, de fato, representar uma grande armadilha para a classe trabalhadora, à medida que se estenda à exploração e à produção de forma permanente e "legitimada" para o espaço privado do trabalhador.

\section{Referências}

ALVES, Giovanni. Trabalho e subjetividade. São Paulo: Editora Boitempo, 2011.

ANTUNES, Ricardo. Coronavírus: o trabalho sob fogo cruzado. São Paulo: Boitempo, 2020.

BRASIL. Lei no 13.467, de 13 de julho de 2017. Altera a Consolidação das Leis do Trabalho (CLT), aprovada pelo Decreto-Lei 5.452, de 10 de maio de 1943, e as Leis 6.019, de 3 de janeiro de 1974, 8.036, de 11 de maio de 1990, e 8.212, de 24 de julho de 1991, a fim de adequar a legislação às novas relações de trabalho.

Lei 12.551, de 15 de dezembro de 2011. Altera o art. 60 da Consolidação das Leis do Trabalho (CLT), aprovada pelo Decreto-Lei 5.452, de 1o de maio de 1943, para equiparar os efeitos jurídicos da subordinação exercida por meios telemáticos e informatizados à exercida por meios pessoais e diretos. 
BRIDI, Maria Aparecida. Teletrabalho em tempos de pandemia e condições objetivas que desafiam a classe trabalhadora. In: OLIVEIRA, Dalila Andrade; POCHMANN, Marcio (Orgs.) A devastação do trabalho: a classe do labor na crise da pandemia. Brasília: Gráfica e Editora Positiva; Confederação Nacional dos Trabalhadores em Educação (CNTE) e Grupo de Estudos sobre Política Educacional e Trabalho Docente, 2020a.

A pandemia Covid-19: crise e deterioração do mercado de trabalho no Brasil. Estudos Avançados, v. 34, n. 100, p. 141-166, 2020 b.

BRIDI, Maria Aparecida; BOHLER, Fernanda., ZANONI, Alexandre. Relatório técnico-científico da pesquisa (parte 1): o trabalho remoto/home-office no contexto da pandemia Covid-19, [recurso eletrônico]. Curitiba: Universidade Federal do Paraná, Grupo de Estudos Trabalho e Sociedade, 2020.

CUIDAR VERBO COLETIVO: Entrevistadoras: Bruna Angotti; Regina Vieira. Entrevistada: Bárbara Castro. [S.I.]. Episódio 5: Trabalho, precarização e pandemia. 31 mai. 2020. Podcast: <https://open.spotify.com/episode/OYDWIrZWKVQxrhkXngyUHv>. Acesso em: 25 Ago. 2020.

DARDOT, Pierre; LAVAL, Christian. A nova razão do mundo: ensaio sobre a sociedade neoliberal. São Paulo: Boitempo, 2016.

DEJOURS, Christophe. A banalização da injustiça social. Rio de Janeiro: Editora Fundação Getúlio Vargas, 2006.

DRUCK, Graça. Trabalho, precarização e resistências: novos e velhos desafios? Caderno CRH, v. 24, n. 1, p. 37-57, Salvador, 2011.

DRUCK, Graça; DUTRA, Renata e SILVA, Selma Cristina. A Contrarreforma neoliberal e a terceirização: a precarização como regra. Caderno $C R H$ [online], v. 32, n. 86, p.289-306, 2019. Disponível em: <https://doi.org/10.9771/ccrh.v32i86.30518>.

HARVEY, David. A condição pós-moderna. 8. ed. São Paulo: Edições Loyola, 1999.

INSTITUTO BRASILEIRO DE GEOGRAFIA E ESTATÍ́STICA (IBGE). Pnad-COVID 2020. Disponível em: <https://covid19.ibge.gov.br/pnad-covid/>. Acesso em: 28 Dez. 2020.

INSTITUTO DE PESQUISA ECONÔMICA APLICADA (IPEA). GÓES, Geraldo S.; MARTINS, Felipe S.; NASCIMENTO, José Antônio S. do. Potencial de teletrabalho na pandemia no Brasil e no mundo. Carta de Conjuntura, n. 47, 2o trimestre, 2020. Disponível em: <https://www.ipea.gov.br/cartadeconjuntura/index.php/2020/06/ potencial-de-teletrabalho-na-pandemia-um-retrato-no-brasil-e-no-mundo/>. 
KREIN; José Dari; PRONI, Marcelo W. Economia informal: aspectos conceituais e teóricos. Brasília: OIT, 2010.

KREIN, José Dari, VÉRAS DE OLIVEIRA, Roberto. Os impactos da Reforma nas condições de trabalho. In: KREIN, José Dari Krein; VÉRAS DE OLIVEIRA, Roberto; FILGUEIRAS. Vitor Araújo. Reforma trabalhista no Brasil: promessas e realidade. Campinas, SP: Curt Nimuendajú, 2019.

LIMA, Ângela M. de S. As faces da subcontratação do trabalho: um estudo com trabalhadoras e trabalhadores da confecção de roupas de Cianorte e região. Tese (Doutorado em Ciências Sociais) - Campinas: Instituto de Filosofia e Ciências Humanas, Universidade Estadual de Campinas (Unicamp), 2009.

OLIVEIRA, Dalila Andrade; POCHMANN, Marcio (Orgs.) A devastação do trabalho: a classe do labor na crise da pandemia. Brasília: Gráfica e Editora Positiva; Confederação Nacional dos Trabalhadores em Educação (CNTE) e Grupo de Estudos sobre Política Educacional e Trabalho Docente, 2020.

OLIVEIRA, Daniela R. de. Do fim do trabalho ao trabalho sem fim: o trabalho e a vida dos trabalhadores digitais em Home Office. Tese (Doutorado em Sociologia) Programa de Pós-Graduação em Sociologia da Universidade Federal de São Carlos, São Carlos, 2017.

ORGANIZAÇÃO INTERNACIONAL DO TRABALHO (OIT). Elementos-chave para um teletrabalho eficaz durante a pandemia de COVID-19. Brasília: OIT, Mar. 2020. Disponível em: <https://www.ilo.org/brasilia/noticias/WCMS_740097/lang--pt/index. htm>. Acesso em: 25 Ago. 2020.

ORGANIZAÇÃO MUNDIAL DE SAÚDE (OMS). O impacto da pandemia na saúde mental das pessoas já é extremamente preocupante. Brasília: OMS, 14 Maio 2020. Disponível em: <https://nacoesunidas.org/oms-o-impacto-da-pandemia-na-saude-mental-das-pessoas-ja-e-extremamente-preocupante/>. Acesso em: 25 Ago. 2020.

ROSENFIELD, Cinara L.; ALVES, Daniela. Autonomia e trabalho informacional: o teletrabalho. Revista de Ciências Sociais. v. 54, n. 1, p.207-233, 2011.

SCHWAB, Klaus. The fourth industrial Revolution. Genève, $\mathrm{CH}$ : World Economic Forum, 2016.

SENNETT, Richard. A corrosão do caráter: o desaparecimento das virtudes com o novo capitalismo. Rio de Janeiro: Bestbolso, 2012.

SLEE, Tom. A nova onda do trabalho precarizado. São Paulo: Editora Elefante, 2017. 
SOUTO MAIOR, Jorge Luiz. Do direito à desconexão do trabalho, 2003. Disponível em: <https://www.jorgesoutomaior.com/uploads/5/3/9/1/53916439/do_direito_ \%C3\%A0_desconex\%C3\%A3o_do_trabalho..pdf. 2003>. Acesso em: 14 Maio 2020.

SRNICEK, Nick. Platform capitalism. Cambridge, UK; Malden, MA: Polity Press, 2016.

WEBTV DA UNIVERSIDADE FEDERAL DO RECÔNCAVO DA BAHIA (UFRB TV). Saúde mental e trabalho remoto em tempos de pandemia. Webinar apresentado por Marcelo Veras. [youtube, UFRB TV, 13.05.2020], 2020. Divulgado pelo Canal UFRB TV. Disponível em: <https://www.youtube.com/watch?v=uDuuGU6IV94>. Acesso em: 08 Set. 2020.

ZUBOFF, Shoshana. Big other: capitalismo de vigilância e perspectivas para uma civilização de informação. In: BRUNO, Fernanda et al. (Orgs.). Tecnopolíticas da vigilância: perspectivas da margem. São Paulo: Boitempo, 2018. 